\title{
Domino reactions of tetrahydroisoquinoline difunctional compounds with 4-isothiocyanato-4-methyl-2-pentanone
}

\author{
Edina Vigóczki, Anasztázia Hetényi, László Lázár, and Ferenc Fülöp* \\ Institute of Pharmaceutical Chemistry, University of Szeged, H-6720 Szeged, Eötvös u. 6., \\ Hungary \\ E-mail:fulop@pharm.u-szeged.hu
}

\begin{abstract}
Trans-9,10-Dimethoxy-3,3,4a-trimethyl-4,4a,6,7,11b,12-hexahydro-3H-pyrimido[6', 1':2,3]imidazo[5,1-a]isoquinoline-1(2H)-thione, cis- and trans-9,10-dimethoxy-3,3,4a-trimethyl4,4a,6,7,12,13-hexahydro-3H,11b $H$-pyrimido[6', $\left.1^{\prime}: 2,3\right]$ pyrimido[6,1-a]isoquinoline- $1(2 H)$ -

thione, trans-10,11-dimethoxy-2,2,14a-trimethyl-1,7,8,12b,13,14a-hexahydro-2H-pyrimido$\left[6^{\prime}, 1 ': 2,3\right][1,3,4]$ oxadiazino[5,4-a]isoquinoline-4(3H)-thione and trans-9,10-dimethoxy-3,3,4atrimethyl-4,4a,6a,7-tetrahydro-3H,6H,12H-pyrimido[6', '’':2,3][1,3,4] oxadiazino-[4,5-b]isoquino-line-1 $(2 H)$-thione, previously unknown ring-annelated isoquinoline derivatives, were prepared by diastereoselective domino ring closures of tetrahydroisoquinoline diamines or hydrazinoalcohols with 4-isothiocyanato-4-methyl-2-pentanone. The relative configurations and predominant conformations of the prepared tetracycles were determined by means of NMR spectroscopy and molecular modeling calculations.
\end{abstract}

Keywords: Diamines, hydrazinoalcohols, tetrahydroisoquinolines, $\beta$-isothiocyanatoketones, domino reactions, tetrahydropyrimidine-2(1H)-thiones

\section{Introduction}

$\beta$-Isothiocyanato-substituted aldehydes and ketones $\mathbf{1}$ are reagents that are widely applied for the synthesis of various heterocyclic compounds. ${ }^{1-3}$ Their reactions with 1,2- or 1,3-aminoalcohols, aminothiols or diamines $\mathbf{2}$ result in pyrimidine-2-thione derivatives condensed with the corresponding 1,3-X,N-heterocycles $(X=O, S, N)(\mathbf{5})$ (Scheme 1). Some compounds of type 5 proved to possess good anti-inflammatory and analgesic activities. ${ }^{3}$ Previous mechanistic studies on these double ring closures revealed that compounds $\mathbf{5}$ were formed by domino processes, ${ }^{4}$ via thiourea 3 and cyclic enamine intermediates 4 , involving intramolecular additions of the $\mathrm{XH}$ groups to the $\mathrm{C}=\mathrm{C}$ bond in $\mathbf{4}^{5}$ 


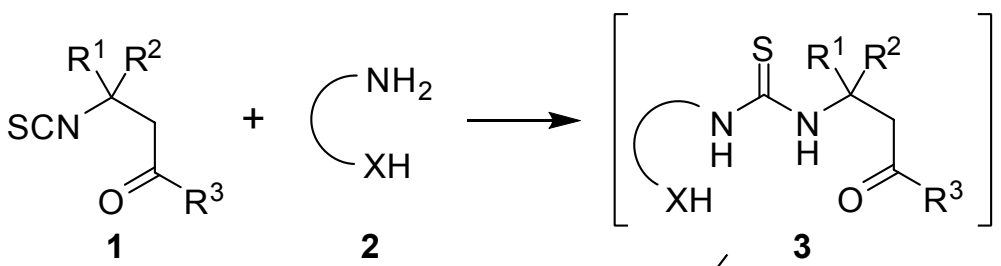

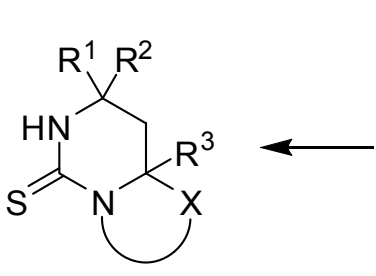

5<smiles>[R]C1=CC([R])([R])NC(=S)N1CC</smiles>

4
$\mathrm{R}^{1}, \mathrm{R}^{2}, \mathrm{R}^{3}: \mathrm{H}$, alkyl $\mathrm{X}: \mathrm{O}, \mathrm{S}, \mathrm{NH}$

\section{Scheme 1}

Despite the numerous examples of the synthetic applicabilities of $\beta$-isothiocyanatoketones, their reactions with tetrahydroisoquinoline difunctional compounds have not yet been reported. Accordingly, as a continuation of our previous work on the preparation and structural analysis of tetrahydroisoquinoline-condensed saturated heterocycles, ${ }^{6-8}$ our present aim was to study the reactions of 4-isothiocyanato-4-methyl-2-pentanone with tetrahydroisoquinoline diamines and hydrazinoalcohols.

\section{Results and Discussion}

\section{Syntheses}

The homologous tetrahydroisoquinoline diamines 8a and $\mathbf{8 b}$ were prepared by a three-step procedure starting from the corresponding $N$-[2-(3,4-dimethoxyphenyl)ethyl]-substituted, $N$ protected amino carboxamides $\mathbf{6 a}, \mathbf{b}$ (Scheme 2). ${ }^{6 \mathrm{a}, \mathrm{b}}$<smiles>COc1ccc(CCNC(=O)[NH+]NC(=O)[O-])cc1OC</smiles>

$6 a, b$

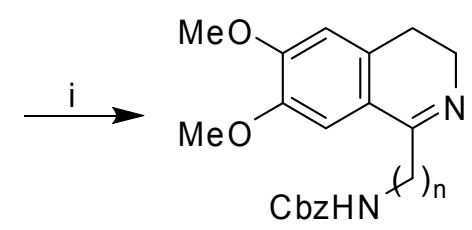

$7 a, b$<smiles>COc1cc2c(cc1OC)C(C=N)NCC2</smiles>

$8 a, b$

$$
\mathrm{n}=1: \mathbf{a}, \quad \mathrm{n}=2: \mathbf{b}
$$

Scheme 2. Reagents and conditions: ${ }^{6 \mathrm{a}, \mathrm{b}}$ i: $\mathrm{POCl}_{3}, \mathrm{CHCl}_{3}$, reflux, $3 \mathrm{~h}, 71-88 \%$; ii: $\mathrm{NaBH}_{4}, \mathrm{MeOH}$, $0{ }^{\circ} \mathrm{C}, 3$ h, then r.t., 3 h, 82-83 \%; iii: $33 \% \mathrm{HBr}$ in $\mathrm{AcOH}$, r.t., 30 min, then $\mathrm{NaOH}, 74-78 \%$. 
The regioisomeric tetrahydroisoquinoline hydrazinoalcohols $\mathbf{1 0}$ and $\mathbf{1 2}$ were obtained by the standard two-step transformation ( $N$-nitrosation and subsequent reduction) of the corresponding amino alcohols 9 and $\mathbf{1 1}$ (Scheme 3$)^{7}$<smiles>COc1cc2c(cc1OC)C(CO)N(N)CC2</smiles><smiles>COc1cc2c(cc1OC)CN(N)C(CO)C2</smiles>

Scheme 3. Reagents and conditions: ${ }^{7}$ i: $\mathrm{NaNO}_{2}, \mathrm{AcOH}, \mathrm{H}_{2} \mathrm{O}$, r.t., 8 h; ii: $\mathrm{LiAlH}_{4}$, THF, r.t., 2 h, $52-67 \%$ (i+ii).

When diamines 8a,b were refluxed with 4-isothiocyanato-4-methyl-2-pentanone ${ }^{9}$ in toluene, diastereomers of the previously unknown ring systems pyrimido[6', $1^{\prime}: 2,3$ ]imidazo$[5,1-a]$ isoquinoline-1(2H)-thione $\mathbf{1 3 a}, \mathbf{b}$ and pyrimido[6', $\left.1^{\prime}: 2,3\right]$ pyrimido[6,1-a]isoquinoline$1(2 H)$-thione 14a,b, differing in the position of the methyl group (Me-4a) and the hydrogen at the annelation (H-11b), were formed in moderate yields, but with considerable diastereo selectivities (Scheme 4).

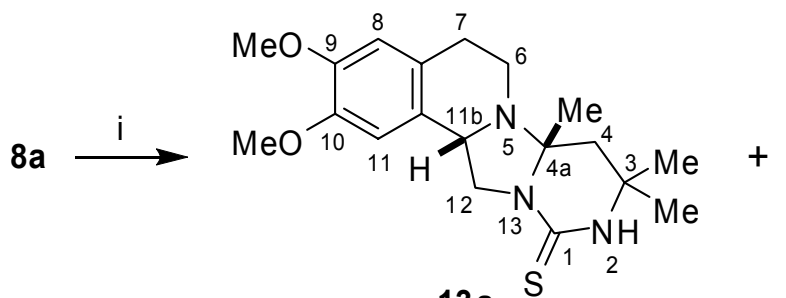

$13 a$

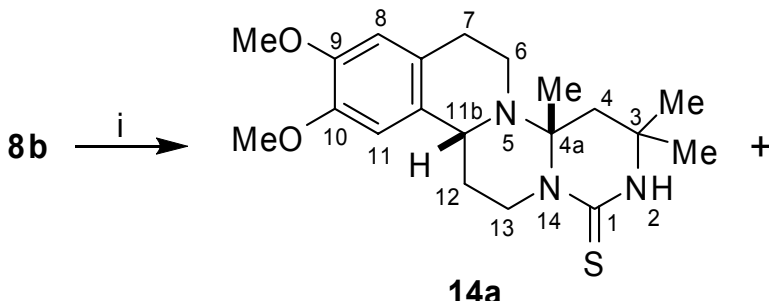

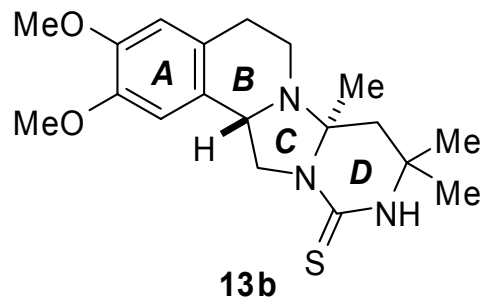

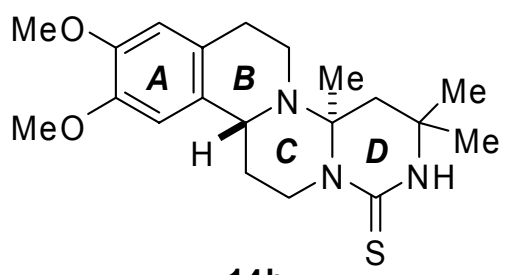

$14 b$

Scheme 4. Reagents and conditions: (i) $\mathrm{MeCOCH}_{2} \mathrm{C}(\mathrm{Me})_{2} \mathrm{NCS}$, toluene, reflux, $12 \mathrm{~h}$; diastereomeric ratios in the crude products: $\mathbf{1 3 a}: \mathbf{1 3 b}=17: 83, \mathbf{1 4 a}: \mathbf{1 4 b}=70: 30$; isolated yields: $23 \%$ 13b, 20\% 14a, 10\% $14 b$. 
The size of the $N, N$-heterocyclic ring formed proved to exert a significant effect on the diastereomeric ratios, the trans isomer 13b being the main product in the ring closure of $\mathbf{8 a}$, while the homologous diamine $\mathbf{8 b}$ gave the cis tetracycle $\mathbf{1 4 a}$ as the major diastereomer. Both the cis and the trans diastereomers of $\mathbf{1 4}$ could be separated by means of column chromatography, but only the major trans isomer $\mathbf{1 3 b}$ could be obtained from the mixture of homologous tetracycles 13; all of our efforts to date to isolate the minor cis compound 13a in diastereomerically pure form have failed. The geometries of the diastereomers were deduced from the presence or lack of the cross-peaks between H-11b and Me-4a in the NOESY spectra.
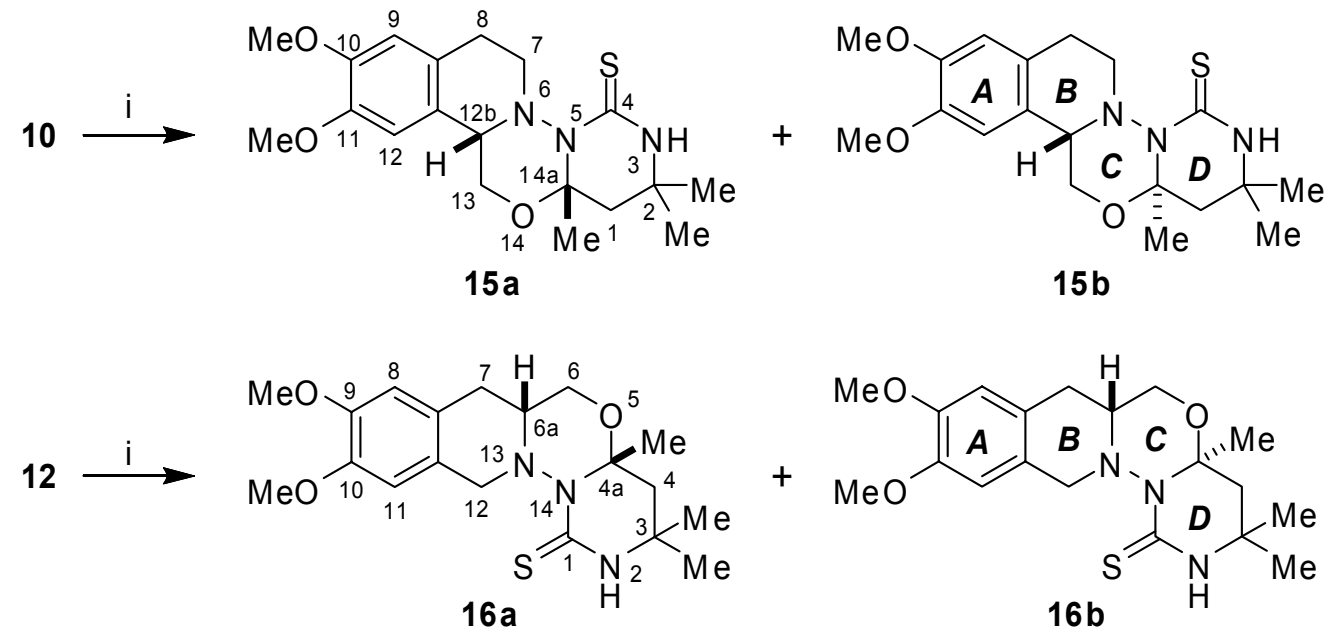

Scheme 5. Reagents and conditions: (i) $\mathrm{MeCOCH}_{2} \mathrm{C}(\mathrm{Me})_{2} \mathrm{NCS}$, toluene, r.t., 20 h; diastereomeric ratios in the crude products: 15a:15b $=\sim 0: \sim 100,16 \mathbf{a}: 16 \mathbf{b}=\sim 0: \sim 100$; isolated yields: $21 \% \mathbf{1 5 b}, 22 \% \mathbf{1 6 b}$.

In the reactions of regioisomeric hydrazinoalcohols 10 and 12 with 4-isothiocyanato-4methyl-2-pentanone, the trans isomers of the new ring systems pyrimido$\left[6^{\prime}, 1^{\prime}: 2,3\right][1,3,4]$ oxadiazino[5,4- $\left.a\right]$ isoquinoline-4(3H)-thione $\mathbf{1 5 b}$ and pyrimido$\left[6^{\prime}, 1^{\prime}-2,3\right][1,3,4]$ oxadiazino[4,5-b] isoquinoline-1 $(2 H)$-thione $\mathbf{1 6 b}$ were formed in moderate yields. Not even traces of the corresponding cis counterparts 15a, 16a could be detected in the crude products. The trans arrangements of the hydrogen at the annelation of rings $\mathrm{B} / \mathrm{C}(\mathrm{H}-12 \mathrm{~b}$ or $\mathrm{H}-6 \mathrm{a})$ and the methyl substituent at the annelation of the rings $\mathrm{C} / \mathrm{D}$ (Me-14a or Me-4a) were deduced from the lack of their cross-peaks in the NOESY spectra of the isolated tetracycles $\mathbf{1 5 b}$ and $\mathbf{1 6 b}$.

\section{Conformations}

For nitrogen-bridged saturated heterocycles, the steric structure can be characterized by conformational equilibria of $c i{ }^{1}-$ trans-cis $^{2}$ type. In the trans structure, rings B/C are transconnected, with the trans-diaxial arrangement of the hydrogen at the annelation and the nitrogen 
lone pair. In the two other configurations, rings $\mathrm{B} / \mathrm{C}$ are cis-connected, where for the cis $^{1}$ conformation the hydrogen at the annelation is in the equatorial position, while for the cis $^{2}$ conformation it is in the axial position relative to tetrahydropyridine ring $\mathrm{B} .{ }^{6-8,10}$ For $\mathbf{1 3 - 1 6}$, only the geometries of the rings $\mathrm{B} / \mathrm{C}$ could be determined, since the thioxo group makes the nitrogen at the neighboring annelation (rings $\mathrm{C} / \mathrm{D}$ ) nearly planar (for the meanings of rings B-D see the Schemes 4 and 5).

To determine the mode of connection of rings $\mathrm{B} / \mathrm{C}, 2 \mathrm{D}$ NMR spectroscopic methods were used, since the cis or trans connections of these rings produce different patterns of the crosspeaks derived from the 1,3-diaxial protons in the NOESY spectra. For $\mathbf{1 3 b}$ and $\mathbf{1 4 b}$, the NOESY spectra exhibited H-11b-H-4 $4_{a x}, H-11 b-H-6_{a x}$, and H-4 $4_{a x}-H-6_{a x}$ NOE cross-peaks, and for 14a H$11 \mathrm{~b}-\mathrm{Me}-4 \mathrm{a}, \mathrm{H}-11 \mathrm{~b}-\mathrm{H}-6_{\mathrm{ax}}$, and Me-4a-H-6 $6_{\mathrm{ax}}$ NOE cross-peaks, which are typical of a transarranged ring $\mathrm{B} / \mathrm{C}$ junction. For $\mathbf{1 5 b}$, the NOESY spectrum revealed Me-2-H-12b, H- $7_{\mathrm{ax}}-\mathrm{H}-13$, $\mathrm{H}-7_{\mathrm{ax}}-\mathrm{Me}-14 \mathrm{a}$ and $\mathrm{H}-13-\mathrm{Me}-14 \mathrm{a}$ NOE cross-peaks, which unequivocally proved the cis connection of rings B/C. For $\mathbf{1 6 b}$, the NOESY cross-peaks for Me-4a with the Me-3, H-12ax, and $\mathrm{H}-6_{\mathrm{ax}}$ protons pointed to a cis $\mathrm{B} / \mathrm{C}$ ring junction.

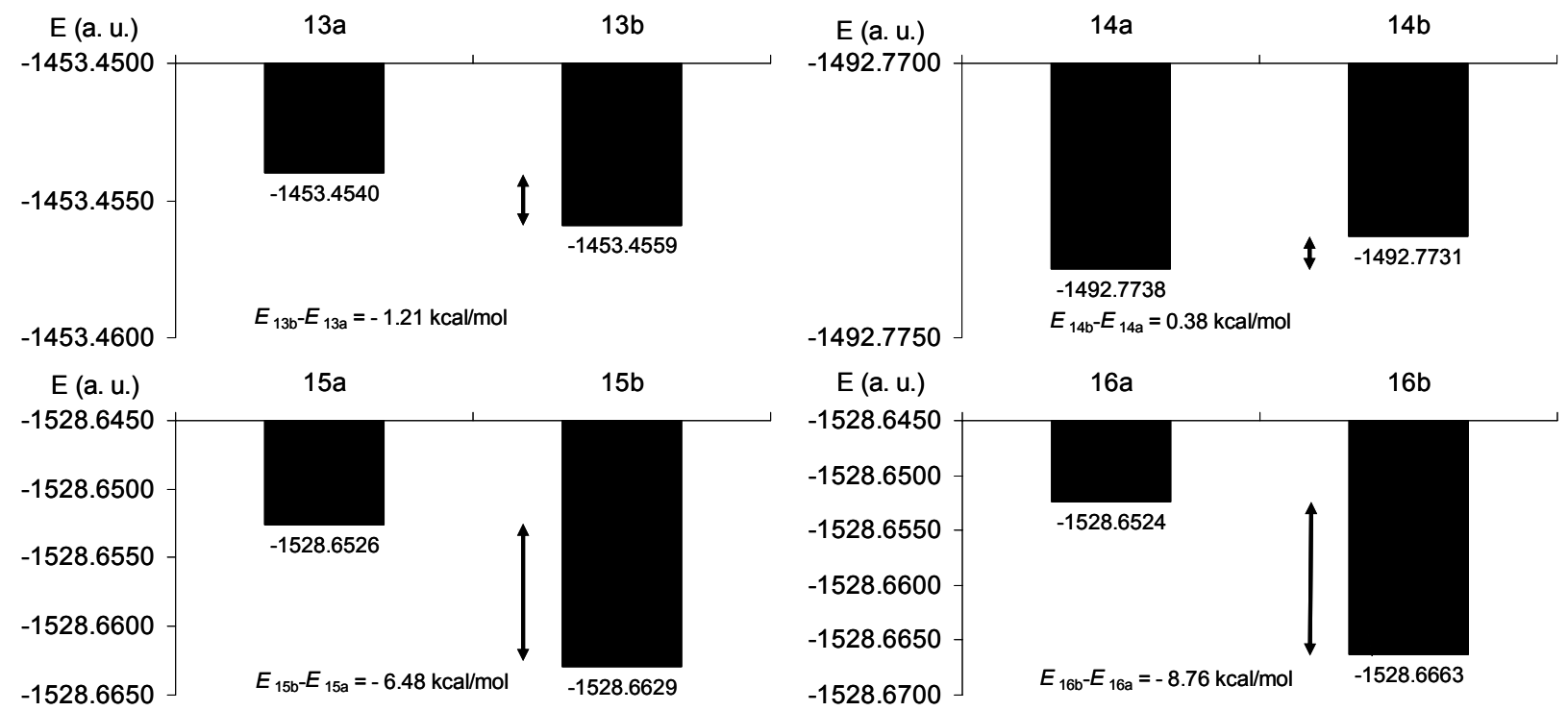

Figure 1. The energy differences between the cis (a) and trans (b) diastereomeric structures of 13-16.

The structures of 13-16 were confirmed by molecular modeling. The conformational protocol comprised a stochastic search via the Merck Molecular Force Field (MMFF94), and a subsequent minimization of the resulting low-energy conformations by using the density functional theory (DFT) quantum mechanical method at the B3LYP/6-311G** level in vacuum for 13-16. The DFT structures converged to the corresponding local minimum of the potential energy surface. The diastereomer energy differences between the cis (a) and trans (b) structures 
proved that for 13 and 14 both isomeric structures are stable and that $\mathbf{1 5 b}$ and the $16 \mathrm{~b}$ are more stable than 15a and 16a, as shown in Fig. 1. This is in good accordance with the observed diastereomeric ratios in the crude tetracylic products 13-16.

The steric structures of the typical minimum-energy molecular structures for 13-16 (Fig. 2) are in good accordance with the experimental results, involving trans-arranged rings $\mathrm{B} / \mathrm{C}$ for $13 \mathrm{~b}, 14 \mathrm{a}$ and $14 \mathrm{~b}$ and the $c i s$ junction of rings $\mathrm{B} / \mathrm{C}$ for $15 \mathrm{~b}$ and $16 \mathrm{~b}$.

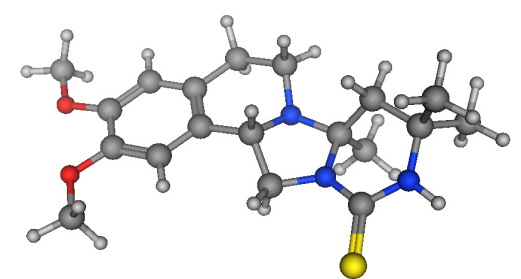

$13 b$

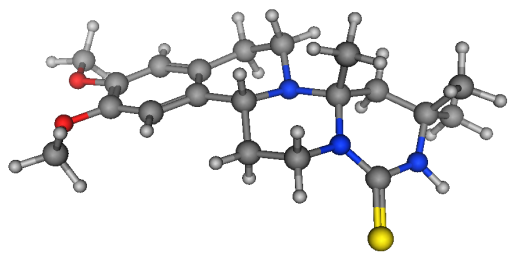

$14 a$

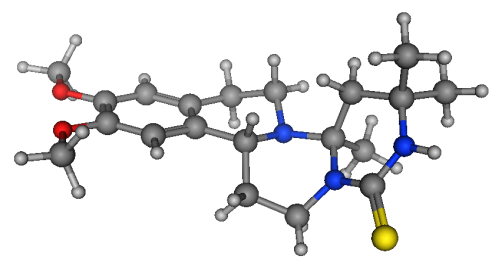

$14 b$

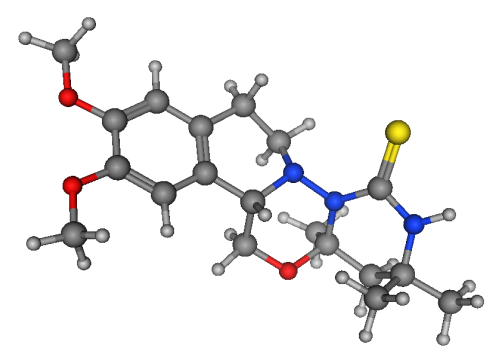

$15 b$

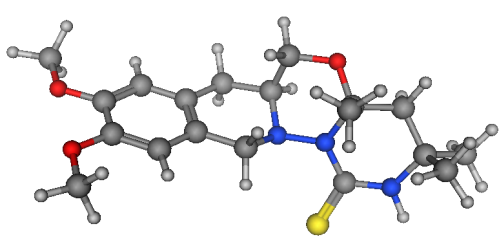

$16 b$

Figure 2. Final predominant minimum energy molecular structures for 13b, 14a, 14b, 15b and 16b, obtained by using B3LYP/6-311G** calculations.

\section{Conclusions}

As a new extension of domino reactions of $\beta$-isothiocyanatoketones with difunctional compounds, diastereomers of partially saturated pyrimido $\left[6^{\prime}, 1^{\prime}: 2,3\right]$ imidazo[5,1-a]isoquinoline1(2H)-thione, pyrimido[6', $\left.1^{\prime}: 2,3\right]$ pyrimido[6,1-a]isoquinoline-1 $(2 H)$-thione, pyrimido$\left[6^{\prime}, 1^{\prime}: 2,3\right][1,3,4]$ oxadiazino[5,4-a]isoquinoline-4(3H)-thione and pyrimido[6', $\left.1^{\prime}-2,3\right][1,3,4]-$ oxadiazino[4,5-b]isoquinoline-1 $(2 H)$-thione were prepared by diastereoselective ring closures of tetrahydroisoquinoline diamines or hydrazinoalcohols with 4-isothiocyanato-4-methyl-2pentanone. Neither the size of the newly formed $N, N$-heterocycle, nor the relative steric position of the substituents at the annelation proved to influence the trans connection of rings $\mathrm{B} / \mathrm{C}$ in the diamine-derived tetracycles. 


\section{Experimental Section}

General. NMR spectra were recorded in $\mathrm{CDCl}_{3}$ at $298 \mathrm{~K}$ on a Bruker Avance III 600 spectrometer operating at $600.2 \mathrm{MHz}$ for ${ }^{1} \mathrm{H}$ and $150.05 \mathrm{MHz}$ for ${ }^{13} \mathrm{C}$. Chemical shifts are reported in $\delta(\mathrm{ppm})$ relative to TMS as internal standard; the values of J are given in Hz. Mass spectra were recorded on a Finnigan MAT 95S instrument, using electron impact ionization. Elemental analyses were performed with a Perkin-Elmer 2400 CHNS elemental analyzer. Melting points were recorded on a Kofler hot-plate microscope apparatus and are uncorrected. For column chromatography, silica gel $60(0.063-0.200 \mathrm{~mm})$ was used. Routine thin-layer chromatography was performed on silica gel $60 \mathrm{~F}_{254}$ plates (Merck, Germany).

General procedure for the preparation of trans-9,10-dimethoxy-3,3,4a-trimethyl4,4a,6,7,11b,12-hexahydro-3H-pyrimido[6',1':2,3] imidazo[5,1-a]isoquinoline-1(2H)-thione (13b) and cis- and trans-9,10-dimethoxy-3,3,4a-trimethyl-4,4a,6,7,12,13-hexahydro$3 H, 11 b H$-pyrimido[6',1':2,3]pyrimido[6,1-a]isoquinoline-1(2H)-thione (14a, 14b)

To a solution of the corresponding tetrahydroisoquinoline diamine $8 \mathbf{a}$ or $8 \mathbf{b}$ (2 $\mathrm{mmol})$ in toluene (20 ml), 4-isothiocyanato-4-methyl-2-pentanone $(315 \mathrm{mg}, 2 \mathrm{mmol})$ was added. The mixture was stirred and refluxed for $12 \mathrm{~h}$, and then evaporated under reduced pressure to afford a yellow oil containing a mixture of the diastereomers of the corresponding tetracycle. The diastereomeric ratios were determined from the ${ }^{1} \mathrm{H}$ NMR spectra of the crude products. Purification of the crude products by column chromatography gave $\mathbf{1 3 b}, \mathbf{1 4 a}$ and $\mathbf{1 4 b}$ as white solids.

Compound 13b. Yield: $165 \mathrm{mg}(23 \%), \mathrm{mp}$ 194-198 ${ }^{\circ} \mathrm{C} .{ }^{1} \mathrm{H}$ NMR $\delta: 1.35$ (3H, s, Me-3), 1.38 (3H, s, Me-3), 1.48 (3H, s, Me-4a), $1.82(1 \mathrm{H}, \mathrm{d}, \mathrm{J}=13.1 \mathrm{~Hz}, \mathrm{H}-4 \mathrm{ax}), 1.97$ (1H, d, J = 13.1 Hz, H$\left.4_{\text {eq }}\right), 2.74(1 \mathrm{H}, \mathrm{d}, \mathrm{J}=15.3 \mathrm{~Hz}, \mathrm{H}-7), 2.85\left(1 \mathrm{H}, \mathrm{dt}, \mathrm{J}=10.6,10.5,4.2 \mathrm{~Hz}, \mathrm{H}-6_{\mathrm{ax}}\right), 2.98-3.05(1 \mathrm{H}$, m, H-7), 3.07-3.11 (1H, m, H-6 $\left.{ }_{\text {eq }}\right), 3.57$ (1H, t, J = 9.9 Hz, H-12), 3.84 (3H, s, OMe), 3.85 (3H, s, OMe), 3.97 (1H, dd, J = 5.7, $9.9 \mathrm{~Hz}, \mathrm{H}-1 \mathrm{lb}), 4.87(1 \mathrm{H}, \mathrm{dd}, \mathrm{J}=5.7,10.2 \mathrm{~Hz}, \mathrm{H}-12), 6.01$ (1H, s, $\mathrm{H}-2), 6.53$ (1H, s, H-11), $6.63(1 \mathrm{H}, \mathrm{s}, \mathrm{H}-8) ;{ }^{13} \mathrm{C}$ NMR $\delta: 24.0,29.3,30.5,33.8,41.2,42.3,52.1$, 54.0, 55.9, 56.0, 56.8, 76.4, 108.1, 111.7, 126.4, 127.1, 147.5, 148.0, 176.3. MS m/z $361 \mathrm{M}^{+}$. Anal. Calcd. for $\mathrm{C}_{19} \mathrm{H}_{27} \mathrm{~N}_{3} \mathrm{O}_{2} \mathrm{~S}$ : C, 63.13; H, 7.53; N, 11.62; Found C, 63.29; H, 7.35; N, 11.51\%.

Compound 14a. Yield: $149 \mathrm{mg}(20 \%), \mathrm{mp}$ 201-203 ${ }^{\circ} \mathrm{C} .{ }^{1} \mathrm{H}$ NMR $\delta: 1.27$ (3H, s, Me-3 $\left.3_{\mathrm{ax}}\right), 1.40$ $\left(3 \mathrm{H}, \mathrm{s}, \mathrm{Me}-3_{\mathrm{eq}}\right), 1.52$ (3H, s, Me-4a), 1.80 (1H, dq, J = 4.7, $\left.13.0 \mathrm{~Hz}, \mathrm{H}-12\right), 2.00$ (1H, d, J = 14.2 Hz, H-4), 2.28 (1H, qd, J = 2.8, 13.1 Hz, H-12), 2.36-2.41 (1H, m, H-6 $\left.{ }_{\mathrm{ax}}\right), 2.40$ (1H, d, J = 14.2 Hz, H-4), 2.58 (1H, dt, J = 3.0, 15.7 Hz, H-7), 2.96 (1H, ddd, J = 5.3, 11.3, 15.7 Hz, H-7), 3.17 $\left(1 \mathrm{H}, \mathrm{ddd}, \mathrm{J}=1.8,5.3,11.3 \mathrm{~Hz}, \mathrm{H}-6_{\mathrm{eq}}\right), 3.45(1 \mathrm{H}, \mathrm{dt}, \mathrm{J}=2.5,13.4 \mathrm{~Hz}, \mathrm{H}-13), 3.83(6 \mathrm{H}, \mathrm{s}, \mathrm{OMe})$, $3.97(1 \mathrm{H}, \mathrm{d}, \mathrm{J}=11.1 \mathrm{~Hz}, \mathrm{H}-1 \mathrm{lb}), 5.57$ (1H, ddd, J = 2.1, 4.5, $13.6 \mathrm{~Hz}, \mathrm{H}-13), 6.54$ (1H, s, H-8), $6.55(1 \mathrm{H}, \mathrm{s}, \mathrm{H}-2), 6.66(1 \mathrm{H}, \mathrm{s}, \mathrm{H}-11) ;{ }^{13} \mathrm{C} \mathrm{NMR} \delta: 18.1,29.4,29.6,30.0,31.0,44.5,44.8,45.9$, 49.4, 55.7, 55.9, 56.1, 73.5, 108.2, 111.2, 126.5, 130.3, 147.4, 147.6, 177.6. MS m/z $375 \mathrm{M}^{+}$. Anal. Calcd. for $\mathrm{C}_{20} \mathrm{H}_{29} \mathrm{~N}_{3} \mathrm{O}_{2} \mathrm{~S}$ : C, 63.97; H, 7.78; N, 11.19; Found C, 64.14; H, 7.81; N, 11.17\%.

Compound 14b. Yield: $75 \mathrm{mg}(10 \%), \mathrm{mp} 160-162{ }^{\circ} \mathrm{C} .{ }^{1} \mathrm{H}$ NMR $\delta: 1.32$ (3H, s, Me-3), $1.36(3 \mathrm{H}$, s, Me-3), 1.60-1.64 (1H, m, H-12), 1.65 (3H, s, Me-4a), 1.81 (1H, d, J = 13.6 Hz, H-4 eq $), 2.12$ 
$\left(1 \mathrm{H}, \mathrm{d}, \mathrm{J}=13.6 \mathrm{~Hz}, \mathrm{H}-4_{\mathrm{ax}}\right), 2.50\left(1 \mathrm{H}, \mathrm{dt}, \mathrm{J}=2.5,10.6 \mathrm{~Hz}, \mathrm{H}-6_{\mathrm{ax}}\right), 2.57-2.67$ (2H, m, H-7, H-12), 2.86-2.92 (1H, m, H-7), 2.95-2.99 (1H, m, H-6eq $) 3.47$ (1H, ddd, J = 5.5, 9.1, $13.1 \mathrm{~Hz}, \mathrm{H}-13$ ), $3.81(3 \mathrm{H}, \mathrm{s}, \mathrm{OMe}), 3.84(3 \mathrm{H}, \mathrm{s}, \mathrm{OMe}), 3.87(1 \mathrm{H}, \mathrm{dd}, \mathrm{J}=7.4,9.3 \mathrm{~Hz}, \mathrm{H}-11 \mathrm{~b}), 5.18(1 \mathrm{H}, \mathrm{dd}, \mathrm{J}=$ 8.8, $12.9 \mathrm{~Hz}, \mathrm{H}-13), 6.32(1 \mathrm{H}, \mathrm{s}, \mathrm{H}-2), 6.54(1 \mathrm{H}, \mathrm{s}, \mathrm{H}-11), 6.56(1 \mathrm{H}, \mathrm{s}, \mathrm{H}-8) ;{ }^{13} \mathrm{C}$ NMR $\delta: 23.5$, 30.3, 30.3, 33.1, 34.9, 38.0, 41.5, 41.9, 49.9, 50.1, 55.9, 55.9, 74.5, 108.9, 111.0, 125.8, 130.9, 147.2, 147.7, 180.5. MS m/z $375 \mathrm{M}^{+}$. Anal. Calcd. for $\mathrm{C}_{20} \mathrm{H}_{29} \mathrm{~N}_{3} \mathrm{O}_{2} \mathrm{~S}: \mathrm{C}, 63.97 ; \mathrm{H}, 7.78 ; \mathrm{N}$, 11.19; Found C, 63.80; H, 7.610; N, 11.07\%.

General procedure for the preparation of trans-10,11-dimethoxy-2,2,14a-trimethyl$1,7,8,12 b, 13,14 a-h e x a h y d r o-2 H$-pyrimido $\left[6^{\prime}, 1^{\prime}: 2,3\right][1,3,4]$ oxadiazino $[5,4-a]$ isoquinoline4(3H)-thione (15b) and trans-9,10-dimethoxy-3,3,4a-trimethyl-4,4a,6a,7-tetrahydro$3 H, 6 H, 12 H$-pyrimido[6',1':2,3][1,3,4]oxadiazino[4,5-b]isoquinoline-1(2H)-thione (16b)

To a solution of the corresponding tetrahydroisoquinoline hydrazinoalcohol $\mathbf{1 0}$ or $\mathbf{1 2}$ (476 mg, 2 $\mathrm{mmol}$ ) in toluene (20 ml), 4-isothiocyanato-4-methyl-2-pentanone (315 mg, $2 \mathrm{mmol}$ ) was added. The mixture was stirred at room temperature for $20 \mathrm{~h}$, and then evaporated in vacuo to afford a yellow crystalline residue. Purification of the crude product by column chromatography gave $\mathbf{1 5 b}$ and $\mathbf{1 6 b}$ as white crystalline substances.

Compound 15b. Yield: $158 \mathrm{mg}(21 \%), \mathrm{mp} 231-232{ }^{\circ} \mathrm{C} .{ }^{1} \mathrm{H}$ NMR $\delta: 1.30$ (3H, s, Me-2 $\left.\mathrm{eq}\right), 1.39$ $\left(3 \mathrm{H}, \mathrm{s}, \mathrm{Me}-2_{\mathrm{ax}}\right), 1.77$ (3H, s, Me-14a), $2.13\left(1 \mathrm{H}, \mathrm{d}, \mathrm{J}=14.0 \mathrm{~Hz}, \mathrm{H}-1_{\mathrm{ax}}\right), 2.23(1 \mathrm{H}, \mathrm{d}, \mathrm{J}=14.0 \mathrm{~Hz}$, H-1 $\left.1_{\text {eq }}\right), 2.79$ (1H, td, J = 4.4, $\left.15.2 \mathrm{~Hz}, \mathrm{H}-8\right), 3.08-3.13$ (1H, m, H-8), 3.42-3.47 (1H, m, H-7 $\mathrm{ax}$ ), $3.82(3 \mathrm{H}, \mathrm{s}, \mathrm{OMe}), 3.87(3 \mathrm{H}, \mathrm{s}, \mathrm{OMe}), 3.87\left(1 \mathrm{H}\right.$, overlapping, $\left.\mathrm{H}-13_{\mathrm{eq}}\right), 3.93(1 \mathrm{H}, \mathrm{d}, \mathrm{J}=11.2 \mathrm{~Hz}$, H-13 $\left.3_{\mathrm{ax}}\right), 3.95-3.99$ (1H, m, H-7 eq $), 4.70(1 \mathrm{H}, \mathrm{dd}, \mathrm{J}=3.6,11.0 \mathrm{~Hz}, \mathrm{H}-12 \mathrm{~b}), 6.48$ (1H, s, H-12), $6.52(1 \mathrm{H}, \mathrm{s}, \mathrm{H}-3), 6.63$ (1H, s, H-9); ${ }^{13} \mathrm{C} \mathrm{NMR} \delta: 24.4,28.6,29.6,30.4,47.8,49.7,50.2,55.8$, 55.9, 56.1, 63.1, 85.1, 109.1, 111.9, 125.2, 127.5, 147.5, 148.2, 181.0. MS m/z $377 \mathrm{M}^{+}$. Anal. Calcd. $\mathrm{C}_{19} \mathrm{H}_{27} \mathrm{~N}_{3} \mathrm{O}_{3} \mathrm{~S}$ : C, 60.45; H, 7.21; N, 11.13; Found C, 60.32; H, 7.07; N, $11.05 \%$.

Compound 16b. Yield: $166 \mathrm{mg}(22 \%), \mathrm{mp} 175-177{ }^{\circ} \mathrm{C} .{ }^{1} \mathrm{H}$ NMR $\delta$ : 1.28 (3H, s, Me-3 $\left.\mathrm{ax}\right), 1.34$ $\left(3 \mathrm{H}, \mathrm{s}, \mathrm{Me}-3_{\mathrm{eq}}\right), 1.65$ (3H, s, Me-4a), $2.08(1 \mathrm{H}, \mathrm{d}, \mathrm{J}=14.0 \mathrm{~Hz}, \mathrm{H}-4), 2.12(1 \mathrm{H}, \mathrm{d}, \mathrm{J}=14.0 \mathrm{~Hz}, \mathrm{H}-$ 4), 2.69 (1H, dd, J = 6.6, $15.4 \mathrm{~Hz}, \mathrm{H}-7), 2.90$ (1H, dd, J = 5.3, $15.4 \mathrm{~Hz}, \mathrm{H}-7), 3.56-3.67$ (2H, m, $\mathrm{H}-6), 3.84$ (3H, s, OMe), 3.85 (3H, s, OMe), 4.04 (1H, d, J = 14.4 Hz, H-12 ax), 4.10-4.15 (1H, m, H-6a), 5.27 (1H, d, J = 14.4 Hz, H-12 $\left.{ }_{\text {eq }}\right), 6.58$ (1H, s, H-11), 6.63 (1H, s, H-8), 6.65 (1H, s, H-2);

${ }^{13} \mathrm{C}$ NMR $\delta: 24.5,27.1,29.2,31.2,47.6,49.6,51.0,51.7,55.6,55.6,63.2,87.2,109.4,111.6$, 124.4, 127.2, 147.1, 147.1, 181.6. MS $m / z 377 \mathrm{M}^{+}$. Anal. Calcd. for $\mathrm{C}_{19} \mathrm{H}_{27} \mathrm{~N}_{3} \mathrm{O}_{3} \mathrm{~S}: \mathrm{C}, 60.45 ; \mathrm{H}$, 7.21; N, 11.13; Found C, 60.29; H, 7.02; N, 11.01\%.

\section{Acknowledgments}

The authors thank the Hungarian Scientific Research Fund (Grant No. OTKA K75433) for financial support. 


\section{References}

1. Sondhi, S. M.; Singh, N.; Rajvanshi, S. Monatsh. Chem. 2004, 135, 119 and references cited therein.

2. (a) Fisyuk, A. S.; Mukanov, A. Yu. Chem. Heterocycl. Comp. (Engl. Transl.) 2003, 39, 277.

(b) Fisyuk, A. S.; Mukanov, A. Yu. Russ. J. Org. Chem. (Engl. Transl.) 2006, 42, 1269.

3. (a) Shondi, S. M.; Goyal, R. N.; Lahoti, A. M.; Singh, N.; Shukla, R.; Raghubir, R. Bioorg. Med. Chem. 2005, 13, 3185. (b). Sondhi, S. M.; Singh, N.; Johar, M.; Kumar, A. Bioorg. Med. Chem. 2005, 13, 6158. (c) Sondhi, S. M.; Jain, S.; Dwivedi, A. D.; Shukla, R.; Raghubir, R. Ind. J. Chem. Sect. B 2008, 47, 136.

4. (a) Tietze, L. F. Chem. Rev. 1996, 96, 115. (b) Tietze, L. F.; Rackelmann, N. Pure Appl. Chem. 2004, 76, 1967. (c) Tietze, L. F.; Brasche, G.; Gericke, K. M. Domino Reactions in Organic Synthesis, Wiley-VCH: Weinheim, 2006. (d) Chapman, C. J.; Frost, C. G. Synthesis 2007, 1.

5. (a) Singh, H.; Kumar, S. J. Chem. Soc., Perkin Trans. 1 1987, 261. (b) Singh, H.; Kumar, S. Tetrahedron 1987, 43, 2177.

6. (a) Hetényi, A.; Martinek, T. A.; Lázár, L.; Zalán, Z.; Fülöp, F. J. Org. Chem. 2003, 68, 5705. (b) Zalán, Z.; Martinek, T. A.; Lázár, L.; Fülöp, F. Tetrahedron 2003, 59, 9117. (c) Lázár, L.; Kivelä, H.; Pihlaja, K.; Fülöp, F. Tetrahedron Lett. 2004, 45, 6199. (d) Zalán, Z.; Hetényi, A.; Lázár, L.; Fülöp, F. Tetrahedron 2005, 61, 5287.

7. Zalán, Z.; Martinek, T. A.; Lázár, L.; Sillapää, R.; Fülöp, F. Tetrahedron 2006, 62, 2883.

8. (a) Szatmári, I.; Martinek, T. A.; Lázár, L.; Fülöp, F. Tetrahedron 2003, 59, 2877. (b) Schuster, I.; Koch, A.; Heydenreich, M.; Kleinpeter, E.; Forró, E.; Lázár, L.; Sillanpää, R.; Fülöp, F. Eur. J. Org. Chem. 2008, 1464. (c) Schuster, I.; Koch, A.; Heydenreich, M.; Kleinpeter, E.; Lázár, L.; Fülöp, F. J. Mol. Struct. 2008, 888, 124.

9. Peretokhin, A. V.; Shutalev, A. D.; Chupin, V. V.; Mergenova, A. M.; Ignatova, L. A.; Malina, Yu. F.; Unkovskii, B. V. Zh. Org. Khim. 1985, 21, 1004.

10. Crabb, T. A. In Cyclic Organonitrogen Stereodynamics; Lambert, J. B., Takeuchi, Y., Eds.; VCH: New York, 1992; pp 253-287. 